\title{
ANALISIS DIAZINON PADA TANAH LAHAN PERTANIAN APEL BUMIAJI MENGGUNAKAN KROMATOGRAFI CAIR KINERJA TINGGI
}

\author{
Marselina Theresia DjueTea ${ }^{\mathrm{a}}$, Akmad Sabarudin ${ }^{\mathrm{b}}$, Hermin Sulistyarti ${ }^{\mathrm{b}}$ \\ a Kimia, Universitas Timor, Kefamenanu, TTU-NTT, Indonesia, email: marselina.yunitea @ unimor.ac.id \\ Jurusan Kimia, Fakultas Matematika dan Ilmu Pengetahuan Alam, Universitas Brawijaya, Malang, Indonesia
}

\section{Article Info}

Article history:

Received: 12 Mei 2020

Received in revised form 5 Juni 2020

Accepted 12 Juni 2020

Doi:

https://doi.org/10.32938/slk.v3i1.1021

\section{Keywords:}

KCKT

Pestisida

Diazinon

\section{Abstrak}

Suatu metode untuk penentuan diazinon dalam sampel tanah telah dikembangkan. Analit diekstraksi dengan asetonitril dari sampe tanah pertanian. Penentuan dan kuantifikasi diazinon dilakukan dengan menggunakan kromatografi cair kinerja tinggi (KCKT) dengan detektor UV. Kondisi optimal untuk analisis diazinon adalah komposisi eluen asetonitril: air 60:40, laju aliran 0,4 mL/menit, dan panjang gelombang $220 \mathrm{~nm}$. Di bawah kondisi optimal, liniearitas diazinon pada konsentrasi 1-25 ppm dengan $\mathrm{R}^{2}$ mendekati 1 yaitu 0,9976. Batas deteksi (LOD) diazinon sebesar 1,19 ppm, sedangkan limit kuantifikasi (LOQ) diazinon sebesar 3,98 ppm. Ketika metode ini diterapkan pada sampel tanah, \% recovery diazinon diatas $80 \%$. Oleh karena itu, dapat dikatakan bahwa metode ini valid dan layak untuk analisis senyawa diazinon dalam tanah. Konsentrasi diazinon dalam sampel tanah berada di bawah LOD dan LOQ $\left(0,577 \mathrm{mgL}^{-1}\right)$, sehingga sampe tanah yang digunakan dalam penelitian ini tidak mengandung diazinon.

\section{Pendahuluan}

Pestisida banyak ditemukan dalam tanah (Sanchez-Brunete et al., 2004) dan dapat menyebabkan masalah lingkungan yang serius karena dapat berpindah ke sistem lingkungan lain seperti air, udara dan rantai makanan manusia (Tette et al., 2016). Pestisida dalam tanah membutuhkan waktu lama untuk terdegradasi dan menyebabkan turunnya biodiversitas organisme dalam tanah (Indrianingsih et al., 2007). Pestisida masuk ke dalam air tanah dan sumber mata air yang dikonsumsi oleh manusia dan juga petani yang berinteraksi langsung dengan pestisida dalam jangka waktu lama akan menimbulkan efek buruk bagi kesehatan, antara lain kanker, depresi, gangguan pernapasan, efek neurologik dan penyakit dermatologi (Indrianingsih et al., 2007). Banyaknya penggunaan pestisida menyebabkan masalah kesehatan yang diduga akibat pencemaran pestisida yang terjadi di Kecamatan Bumiaji, Kota Batu, yang mana terdapat 75 anak berkebutuhan khusus (ABK), dan dari sejumlah tersebut sebagian besar mengalami kelumpuhan otak (Pertanian Sehat, 2012).

Pestisida organofosfat banyak digunakan untuk pengendalian hama dibidang pertanian diseluruh dunia, untuk mengendalikan hama (serangga, tikus, jamur, dan gulma) (Mulder et al., 2019). Residunya dibawa oleh pekerja pertanian ke lingkungan rumah tangga sehingga menyebabkan paparan melalui kontak dengan pakaian dan kulit (Griffith et al., 2019). Diazinon merupakan insektisida organofosfat dengan bobot molekul 304,35 g/mol, titik didih 83 - 94 ${ }^{\circ} \mathrm{C}$, tekanan uap $4,6 \times 10^{-5} \mathrm{mmHg}$ pada suhu $10{ }^{\circ} \mathrm{C}, 1,4 \times 10^{-4} \mathrm{mmHg}$ pada suhu $20{ }^{\circ} \mathrm{C}$, dan $1,1 \times 10^{-3} \mathrm{mmHg}$ pada suhu $40{ }^{\circ} \mathrm{C}$, kelarutan dalam air $0,004 \%$ pada suhu $20{ }^{\circ} \mathrm{C}$ dan larut dalam pelarut organik. Struktur diazinon dengan nama kimianya O,O-dietil-O-(2-isopropil-6-metil-4-4-pirimidil) fosforotioat, dapat dilihat pada Gambar 1. Diazinon menyerap sinar UV pada panjang gelombang $247 \mathrm{~nm}$ (Hartanti et al., 2012).

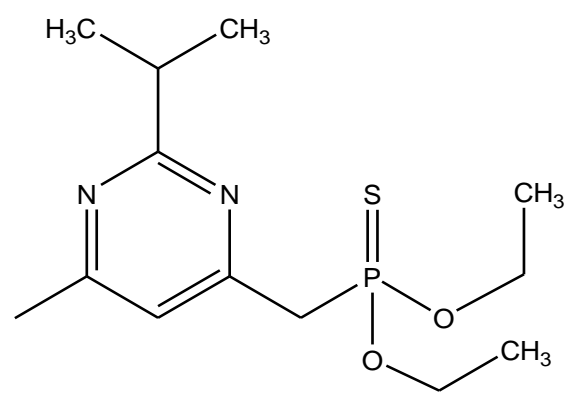

Gambar 1. Struktur Diazinon

Diazinon digunakan untuk mengendalikan kutu daun, lalat buah, dan kutu loncat pada buah apel, dan anggur. Batas maksimum residu yang diperbolehkan di Indonesia pada buah apel, anggur dan pir sebesar $0,5 \mathrm{mg} / \mathrm{kg}$ (Syahbirini dan Pumama, 2001).

Metode kromatografi cair kinerja tinggi merupakan suatu metode analisis yang akurat dan sensitif untuk penentuan secara kualitatif maupun kuantitatif senyawa yang tidak mudah menguap. Keuntungannya adalah waktu analisis yang cepat, biaya yang murah, dan mampu menganalisis senyawa dengan stabilitas rendah (Nurhamidah, 2005). Metode analisis pestisida diazinon dalam sampel air dan tanah menggunakan KCKT dengan detektor UV pada panjang gelombang $245 \mathrm{~nm}$ memiliki limit kuantifikasi pada sampel air 0,1 ng/ml sedangkan pada sampel tanah sebesar $1 \mathrm{ng} / \mathrm{ml}$ dan \% recovery berkisar 86 sampai $102 \%$ (Sánchez et al., 2007).
Dalam penelitian ini, dilakukan optimasi komposisi eluen, optimasi laju alir, dan optimasi panjang gelombang. Selanjutnya dilakukan uji validitas, yang terdiri dari uji linearitas, uji akurasi, limit of detection (LOD) dan limit of quantification (LOQ). Selanjutnya sampel tanah di analisis menggunakan metode KCKT dengan kondisi yang optimum yang diperoleh.

\section{Metode}

\subsection{Pengambilan sampel tanah}

Sampel tanah diambil dari lahan pertanian apel Kecamatan Bumiaji, Kota Batu, Malang. Sampel tanah diambil pada 5 titik yang berbeda. Tanah yang diambil berada pada kedalaman $0-10 \mathrm{~cm}$, diayak dan disimpan dalam plastik kedap udara pada suhu $\pm 4{ }^{\circ} \mathrm{C}$ sampai sampel tanah akan dianalisis.

2.2 Ekstraksi sampel menggunakan ultrasonic solvent extraction (USE)

Sampel tanah ditimbang $20 \mathrm{~g}$, ditambahkan dengan $60 \mathrm{ml}$ asetonitril. Distirer selama 1 jam dan disonikasi selama 2 menit. Ekstrak disaring menggunakan kertas saring $0,2 \mu \mathrm{m}$. Selanjutnya dianalisis menggunakan KCKT.

2.3 Pembuatan larutan standar pestisida diazinon

Pembuatan larutan induk standar diazinon 500 ppm dilakukan dengan memipet 45,44 $\mu \mathrm{L}$ standar diazinon dan di masukan kedalam labu takar $100 \mathrm{~mL}$. Kemudian diencerkan dengan asetonitril sampai tanda batas. Larutan diazinon dengan konsentrasi lebih rendah dibuat dengan cara mengencerkan larutan induk diazinon hingga mencapai volume yang sesuai dengan menggunakan asetonitril. 2.4 Penentuan komposisi eluen asetonitril:air yang optimum

Larutan standar diazinon yang sudah dipreparasi diambil sebanyak $\pm 1 \mathrm{~mL}$ menggunakan spuit $1 \mathrm{cc}$. Selanjutnya diinjeksikan pada KCKT dengan kondisi instrumen KCKT, yaitu suhu ruang, kolom C-8 250L x $4 \mathrm{~mm}$, laju alir 0,4 $\mathrm{mL} / \mathrm{menit}$, detektor UV $240 \mathrm{~nm}$, dan eluen asetonitril dan air (80:20), (70:30), (60:40), (50:50), (40:60).

\subsection{Penentuan laju alir yang optimum}

Penentuan laju alir optimum dilakukan dengan kondisi instrumen KCKT, dengan komposisi eluen yang sudah terpilih (kondisi optimum), dengan variasi laju alir $0,2 \mathrm{~mL} / \mathrm{min} ; 0,4 \mathrm{~mL} / \mathrm{min} ; 0,6 \mathrm{~mL} / \mathrm{min} ; 0,8 \mathrm{~mL} / \mathrm{min} ; 1,0 \mathrm{~mL} / \mathrm{min}$.

\subsection{Penentuan panjang gelombang optimum}

Penentuan panjang gelombang optimum dilakukan dengan kondisi instrumen KCKT, dengan komposisi eluen dan laju alir yang sudah terpilih (kondisi optimum), dengan variasi panjang gelombang yang digunakan, yaitu $220 \mathrm{~nm}, 230 \mathrm{~nm}, 240 \mathrm{~nm}, 250 \mathrm{~nm}, 260 \mathrm{~nm}$.

\subsection{Validasi metode}

Validasi metode KCKT meliputi uji linearitas, ketepatan, limit of detection (LOD) dan limit of quantification (LOQ).

\subsection{Analisis diazinon dari ekstrak tanah dengan metode spiking}

Untuk penentuan keberadaan diazinon dalam tanah dilakukan dengan cara mengambil sampel tanah yang sudah dipreparasi, disonikasi selama 300 detik kemudian diambil sebanyak $\pm 1 \mathrm{~mL}$. Selanjutnya diinjeksikan pada KCKT melalui penyaringan dengan kertas saring mikron $0,2 \mu \mathrm{m}$ dengan kondisi optimum yang diperoleh sebelumnya. Selanjutnya, dilakukan perbandingan hasi kromatogram sampel tanah dengan kromatogram standar diazinon. Apabila dalam kromatogram sampel tanah memiliki waktu retensi yang sama dengan kromatogram standar diazinon, maka dapat dinyatakan bahwa keberadaan diazinon dalam ekstrak tanah adalah benar.

\section{Hasil dan Pembahasan}

Optimasi metode KCKT dan identifikasi pestisida diazinon, meliputi laju alir, komposisi eluen, dan panjang gelombang. Selanjutnya dilakukan validasi untuk mengetahui kelayakan metode KCKT dan analisis diazinon dalam sampel tanah dengan kondisi optimum. 


\subsection{Optimasi komposisi eluen}

Optimasi komposisi eluen dilakukan dengan metode elusi isokratik yaitu komposisi eluen tetap selama analisis dan menggunakan pestisida diazinon $10 \mathrm{~g}$ dengan kemurnian $10 \%$. sebagai zat standar. Eluen yang digunakan adalah asetonitril dan air.

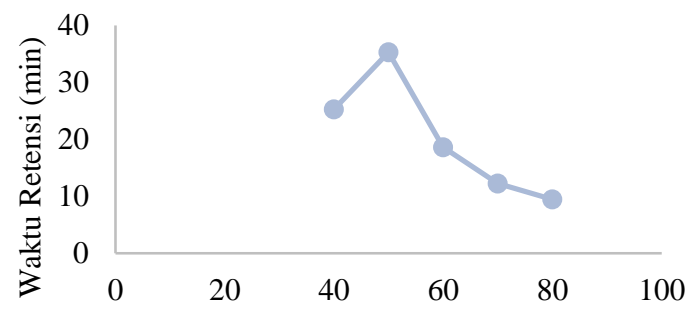

$\%$ Asetonitrile

Gambar 2. Pengaruh komposisi asetonitril terhadap waktu retensi

Gambar 2 menunjukan bahwa semakin banyak pelarut asetonitril yang digunakan maka waktu retensi senyawa semakin cepat. Hal ini disebabkan oleh kolom yang digunakan bersifat non polar dan pelarutnya polar, sehingga senyawa yang bersifat lebih non polar akan tertahan lebih lama di kolom. Komposisi eluen asetonitril:air yang optimum adalah 60:40, dengan waktu retensi senyawa diazinon 18,64 , dan waktu retensi yang tidak terlalu lama yaitu di bawah 20 menit. Ratio optimum komposisi eluen yang diperoleh pada penelitian ini memberikan \% recovery sebesar $87,3 \%$ lebih kecil dari \% recovery yang dilaporkan oleh Sánchez et al. (2007), yaitu 92 - 96 \% dengan komposisi eluen asetonitril air $65: 35$. Nilai \% recovery berada pada rentang \% recovery yang dapat diterima (80-110\%) untuk konsentrasi analit 1 ppm (Harmita, 2004).

Identifikasi waktu retensi senyawa diazinon dilakukan dengan komposisi eluen yang optimum yaitu asetonitril:air (60:40). Standar diazinon yang digunakan adalah diazinon pestanal ${ }^{\mathrm{TM}}$ yang merupakan standar untuk kelas KCKT dengan tingkat kemurnian 98,6\% dengan bentuk sediaan berupa cairan berwarna coklat kekuningan. Selanjutnya, standar diazinon dipreparasi melalui proses pengenceran menggunakan pelarut asetonitril sampai diperoleh larutan standar diazinon dengan konsentrasi $25 \mathrm{ppm}$. Gambar 3 menunjukan puncak kromatogram standar diazinon 25 ppm keluar pada waktu retensi 18,983 dengan luas puncak 441375 .

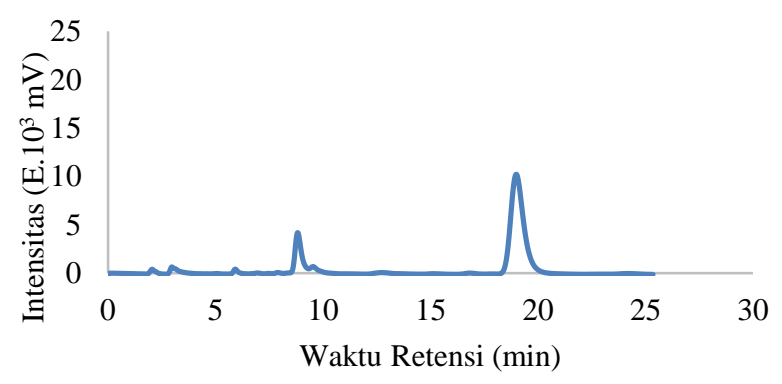

Gambar 3. Kromatogram standar diazinon 25 ppm

(Kondisi analisis: Kolom Lichrospher ${ }^{\circledR} 100$ RP-8, $10 \mu \mathrm{m}, 250$ mm x 4 mm i.d; V.sampel 2 $\mu \mathrm{L}$; Komposisi Asetonitril:Air (60:40); Laju alir: $0,4 \mathrm{~mL} / \mathrm{min} ; \lambda=240 \mathrm{~nm}$ )

\subsection{Optimasi laju alir}

Optimasi laju alir bertujuan untuk mengetahui kondisi laju alir optimum. Laju alir menunjukan tingkat kecepatan aliran zat tertentu persatuan waktu. Secara teoritis laju alir tidak menurunkan atau menaikan derajat pemisahan, tetapi mempercepat atau memperlambat laju pemisahan. Optimasi laju alir dilakukan dengan lima variasi laju alir yaitu, $0,2 \mathrm{~mL} / \mathrm{min} ; 0,4 \mathrm{~mL} / \mathrm{min}$; $0,6 \mathrm{~mL} / \mathrm{min} ; 0,8 \mathrm{~mL} / \mathrm{min} ; 1,0 \mathrm{~mL} / \mathrm{min}$. Pengaruh laju alir terhadap waktu retensi senyawa diazinon dapat dilihat pada Gambar 4.

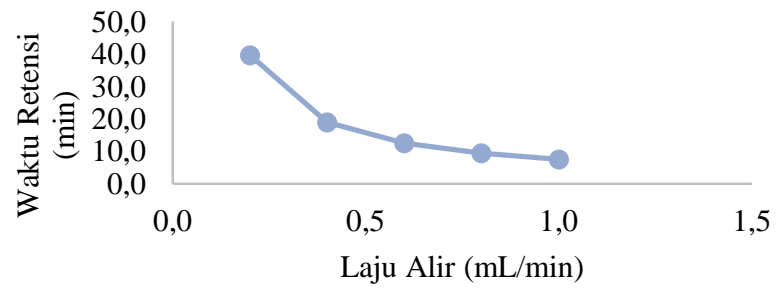

Gambar 4. Pengaruh laju alir terhadap waktu retensi standar diazinon
(Kondisi analisis: Kolom Lichrospher ${ }^{\circledR} 100 \mathrm{RP}-8,10 \mu \mathrm{m}, 250 \mathrm{~mm} \times 4 \mathrm{~mm}$ i.d; V.sampel 2 $\mu \mathrm{L}$; Komposisi Asetonitril:Air $(60: 40) ; \lambda=240 \mathrm{~nm})$

Gambar 4 menunjukan bahwa semakin besar laju alir maka waktu retensi yang diperlukan untuk analisis diazinon semakin cepat. Maka kondisi laju alir optimum untuk analisis diazinon yaitu pada laju alir $0,4 \mathrm{~mL} / \mathrm{min}$. Dimana waktu analisis cepat yaitu dibawah 20 menit dan luas puncak senyawa yang besar yaitu 427586 untuk diazinon. Laju alir yang diperoleh dengan komposisi asetonitril:air (60:40) $0,4 \mathrm{~mL} / \mathrm{min}$ lebih lambat dibandingkan dengan yang dilaporkan oleh Tang et al. (2009), yaitu sebesar $1 \mathrm{~mL} / \mathrm{min}$ dengan kompisisi asetonitril:air (40:60). Hal ini disebakan oleh kolom C-18 yang besifat nonpolar sehingga menahan komponen nonpolar lebih lama di kolom.

\subsection{Optimasi panjang gelombang}

Optimasi panjang gelombang dilakukan pada lima titik yaitu: $220 \mathrm{~nm}$, $230 \mathrm{~nm}, 240 \mathrm{~nm}, 250 \mathrm{~nm}$ dan $260 \mathrm{~nm}$. Pengaruh panjang gelombang terhadap luas puncak disajikan pada Gambar 5 .

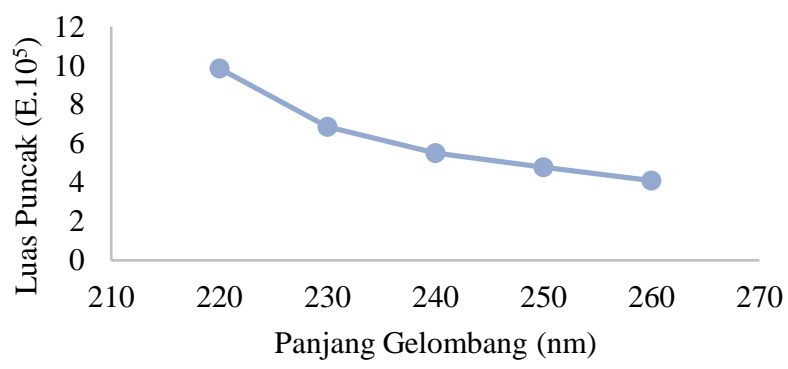

Gambar 5. Pengaruh panjang gelombang terhadap luas puncak standar diazinon

Gambar 5 menunjukan bahwa pada panjang gelombang $220 \mathrm{~nm}$ memiliki luas puncak paling besar. Adanya luas puncak yang besar menunjukan bahwa sensitivitas yang tinggi sehingga diazinon dapat terdeteksi. Oleh karena itu, panjang gelombang optimum untuk diazinon berada pada panjang gelombang $220 \mathrm{~nm}$. Panjang gelombang ini berada pada kisaran panjang gelombang diazinon yaitu $200-280$ (Shemer dan Linden, 2006).

\subsection{Validasi metode KCKT}

Validasi metode dilakukan pada kondisi optimum yaitu komposisi eluen asetonitril:air (60:40), laju alir $0,4 \mathrm{~mL} / \mathrm{min}$, dan panjang gelombang $220 \mathrm{~nm}$. Kurva baku standar diazinon dapat dilihat pada Gambar 6.

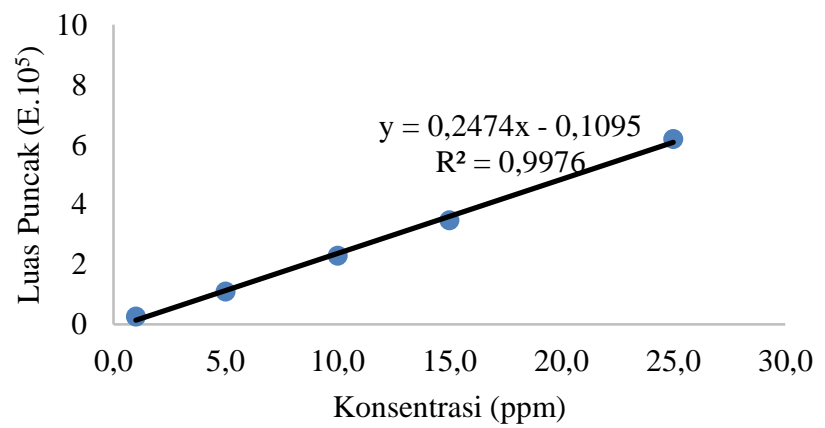

Gambar 6. Kurva baku standar diazinon

(Kondisi analisis: Kolom Lichrospher ${ }^{\circledR} 100 \mathrm{RP}-8,10 \mu \mathrm{m}, 250 \mathrm{~mm} \times 4 \mathrm{~mm}$ i.d; V.sampel 2 $\mu \mathrm{L}$; Fase Gerak Asetonitril:Air (60:40); Laju Alir: 0,4 mL/min; $\lambda=220 \mathrm{~nm}$ )

Gambar 6 menunjukan bahwa tingkat linearitas larutan standar diazinon pada konsentrasi 1-25 ppm dengan nilai linearitas $\left(\mathrm{R}^{2}\right)$ mendekati 1 yaitu 0,9976 Kemudian uji batas deteksi (LOD) yang bertujuan untuk mengetahui batas konsentrasi terkecil dari diazinon yang dapat terukur oleh instrumen KCKT dan batas kuantifikasi (LOQ) yang menunjukan batas terkecil analit yang dapat terdeteksi secara kuantitatif diperoleh pada konsentrasi 1,19 ppm (untuk LOD) dan 3,98 ppm (untuk LOQ).

Parameter ketepatan menggunakan metode spiking yang didasarkan pada \% recovery. Nilai \% recovery pada penelitian ini dapat dilihat pada Tabel 1 .

Tabel 1. Nilai \% recovery diazinon dalam tanah $(n=3)$

\begin{tabular}{ccccc}
\hline Senyawa & $\begin{array}{c}\text { Sampel } \\
\text { tanah }\end{array}$ & $\begin{array}{c}\text { Konsentrasi standar } \\
\text { yang ditambahkan } \\
(\mathbf{p p m})\end{array}$ & $\begin{array}{c}\text { Konsentrasi } \\
\text { terukur } \\
(\mathbf{p p m})\end{array}$ & $\begin{array}{c}\% \\
\text { recovery }\end{array}$ \\
\hline \multirow{2}{*}{ Diazinon } & $\mathrm{A}$ & 0 & 0,17 & - \\
& $\mathrm{B}$ & 5 & 0,19 & 87,73 \\
\hline
\end{tabular}


Pada Tabel di atas diketahui bahwa nilai \% recovery dizinon yang diperoleh berada pada rentang yang dapat diterima yaitu 80-110\% (Harmita, 2004).

\subsection{Analisis diazinon dalam sampel tanah}

Konsentrasi rata-rata diazinon dalam sampel tanah yaitu $0,577 \mathrm{ppm}$. Konsentrasi yang lebih rendah dari batas deteksi dan batas kuantifikasi yaitu batas yang dapat dideteksi dalam penelitian ini maka dapat disimpulkan bahwa pada sampel tanah yang digunakan dalam penelitian ini tidak mengandung senyawa diazinon.

\section{Simpulan}

Kondisi optimum metode KCKT yang digunakan untuk analisis diazinon dalam sampel tanah adalah pada komposisi fase gerak asetonitril:air (60:40) dengan sistem elusi isokratik, laju alir $0,4 \mathrm{~mL} / \mathrm{min}$ dan panjang gelombang UV $220 \mathrm{~nm}$. Liniearitas larutan standar diazinon yang cukup baik pada konsentrasi 1-25 ppm dengan $\mathrm{R}^{2}$ mendekati 1 yaitu 0,9976. Batas deteks (LOD) diazinon sebesar 1,19 ppm, sedangkan limit kuantifikasi (LOQ) diazinon sebesar 3,98 ppm, dan \% recovery diatas $80 \%$. Oleh karena itu, dapat dikatakan bahwa metode ini valid dan layak untuk analisis senyawa diazinon dalam tanah. Konsentrasi diazinon dalam sampel tanah berada di bawah LOD dan LOQ $(0,577$ $\mathrm{mgL}^{-1}$ ), sehingga dapat disimpulkan bahwa diazinon tidak ditemukan dalam sampel tanah yang dianalisis.

\section{Pustaka}

Griffith, W. C., Vigoren, E. M., Smith, M. N., Thompson, B., Coronado, G. D., Elaine, M., Sciences, O. H., Communication, R., Program, P., \& Hutchinson, F. 2019. Application of Improved Approach to Evaluate a Community Intervention to Reduce Exposure of Young Children Living in Farmworker Households to Organophosphate Pesticides. J Expo Sci Environ Epidemiol, 29(3), 358-365. https://doi.org/10.1038/s41370-0180028-y.Application

Harmita. 2004. Petunjuk Pelaksanaan Validasi Metode dan Cara Perhitungannya. Majalah Ilmu Kefarmasian, 1(3), 117-135.

Hartanti, E., Mahatmanti, F., \& Susatyo, E. (2012). Sintesis Kitosan_Bentonit serta Aplikasinya sebagai Penurun Kadar Insektisida Jenis Diazinon. Indonesian Journal of Chemichal Science, 1, 111-115.

Indrianingsih, A., Nisa, K., Wahono, S., Taufika, V., Rosdya, Damayanti, E., \& Maryana, R. 2007. Analisis Residu Pestisida dalam Tanah dan Umbi Bawang Merah di Lahan Pasir Sanden , Bantul, Yogyakarta dengan Kromatografi Gas. Seminar Nasional Rekayasa Kimia Dan Proses 2007 ISSN: $1411-4216,181-185$.

Mulder, T. A., Dries, M. A. Van Den, Korevaar, T. I. M., \& Ferguson, K. K. 2019. Organophosphate Pesticides Exposure in Pregnant Women and Maternal and Cord Blood Thyroid Hormone Concentrations.

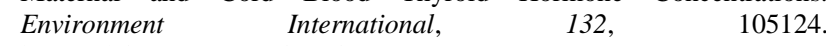
https://doi.org/10.1016/j.envint.2019.105124

Nurhamidah. 2005. Penentuan Kondisi Optimum HPLC untuk Pemisahan Residu Pestisida Imidakloprid, Profenofos, dan Deltametrin pada Cabai (Capsicumannum). Jurnal Ilmu-Ilmu Pertanian Indonesia, 7(2), 87-93.

Pertanian Sehat. 2012. https://pertaniansehat.com/read/2012/08/09/pentingnyaanalisis-residu-pestisida.html, diakses tanggal 13 Januari 2016.

Sánchez, M. E., Méndez, R., Gómez, X., \& Martín-Villacorta, J. 2007. Determination of Diazinon and Fenitrothion in Environmental Water and Soil Samples by HPLC. Journal of Liquid Chromatography and Related Technologies, 26, 483-497. https://doi.org/10.1081/JLC-120017184

Sanchez-Brunete, C., Albero, B., \& Tadeo, J. 2004. Multiresidue Determination of Pesticides in Soil by Gas Chromatography - Mass Spectrometry Detection. Journal of Agricultural and Food Chemistry, 52, 1445-1451.

Shemer, H., \& Linden, K. G. 2006. Degradation By-product Formation and of Diazinon in Water During UV and $\mathrm{UV} / \mathrm{H}_{2} \mathrm{O}_{2}$ Treatment. Journal of $\begin{array}{lll}\text { Hazardous } & \text { Materials, } & \text { 136(3), 553-559. }\end{array}$ https://doi.org/10.1016/j.jhazmat.2005.12.028

Syahbirini, G., \& Pumama, H. 2001. Pesticide Residues in Three Kinds of Imported Fruits. Buletin Kimia, 1, 113-118.

Tang, J., Zhang, M., Cheng, G., \& Lu, Y. 2009. Preparation and Evaluation of Sol-Gel Glass-Based Immunoaffinity Column and Their Potential Use in Determination of Diazinon in Water and Soil Samples with High Performance Liquid Chromatography. Analytical Letters, 42, 243-254. https://doi.org/10.1080/00032710802585709

Tette, P., Guidi, L., Gloria, M., \& Fernandes, C. 2016. Talanta Pesticides in Honey: A Review on Chromatographic Analytical Methods. Talanta, 149, 124-141. https://doi.org/10.1016/j.talanta.2015.11.045 